\title{
0698 EXPOSURE TO THE EDUCATIONAL SYSTEM AS A PROTECTIVE FACTOR FOR INJURIES
}

J F Ungaro*, J B Barassi, M I Galindez, G H De Hoyos Correspondence: Universidad Nacional de Mar del Plata, Funes 3350 - Nivel 4 - Facultad de Ciencias de la Salud y Servicio Social - Mar del Plata 7600, Argentina

10.1136/ip.2010.029215.698

Introduction The exposure to the educational system of youth from 16 to 22 years, residents in Neuquen, Argentina, is analysed as a protective factor for the occurrence of injuries.

Method This is a descriptive study based on interviews carried out to 480 young participants, 240 of whom were in school and 240 of whom were not. Participants were questioned regarding their sociodescriptive characteristics, health habits use of safety devices, alcohol consumption-, opinions, peer and family relationships and previous ambulatory care or hospital admission/s for an injury. Factorial analysis of multiple correspondences and hierarchy classification were performed for each dimension, thus obtaining five typological variables. The relationship among the variables obtained was analysed by means of the value test obtained by a hypergeometric distribution and $\chi^{2}$ test.

Results Youth in the school system showed in a larger proportion habits, opinions and relationships that could be considered protective factors: helmet and seat belt use, a responsible attitude towards alcohol use, a positive opinion of self-care and a larger capacity for interpersonal communication. The relationship of these characteristics to a previous ambulatory care or hospital admission/s for an injury was, in all cases, statistically significant $(\mathrm{p}<0.01)$.

Conclusion Participation of young people in the educational system could favour activities and identification with peers that propitiate their emotional support and the development of healthy life projects. On the other side, those not in the school system seems to focus in risky recreational activities like weekend binge drinking. 